\title{
Stakeholder Perspectives on COVID-19 and Household Water Access in Vulnerable Communities in the Mekong Region
}

\author{
Louis Lebel $\mathbb{1}^{1} \cdot$ Nilar Aung $^{2}$ - Chau Thi Minh Long ${ }^{3}$ - Phoummixay Siharath ${ }^{4}$ Phimphakan Lebel ${ }^{1} \cdot$ Hap Navy ${ }^{5}$. \\ Chu Thai Hoanh ${ }^{6}$. Boripat Lebel $\mathbb{1}^{1}$
}

Received: 26 November 2021 / Accepted: 15 February 2022 / Published online: 2 March 2022

(c) The Author(s), under exclusive licence to Springer Science+Business Media, LLC, part of Springer Nature 2022

\begin{abstract}
The COVID-19 pandemic has underlined the importance of safe access to sufficient clean water in vulnerable communities, renewing interest in water, sanitation and hygiene (WASH) programs and related targets under Sustainable Development Goal 6 (SDG 6). The purpose of this study was to better understand the obstacles to water access in vulnerable communities and identify ways they might be addressed in five countries in the Mekong Region (Cambodia, Laos, Myanmar, Thailand, Vietnam). To this end, qualitative interviews with 50 government officials and development or health experts were complimented with a quantitative survey of the experiences and views of individuals in 15 vulnerable communities. There were several key findings. First, difficulties in accessing sufficient clean water for drinking and hygiene persist in certain vulnerable communities, including informal urban settlements, remote minority villages, and migrant worker camps. Second, limited rights, high prices, and remote locations were common obstacles to household access to improved water sources. Third, seasonal differences in the availability of clean water, alongside other disruptions to supply such as restrictions on movement in COVID-19 responses, drove households towards lower quality sources. Fourth, there are multiple threats to water quality from source to consumption that should be addressed by monitoring, treatment, and watershed protection. Fifth, stakeholder groups differ from each other and residents of vulnerable communities regarding the significance of water access, supply and quality difficulties, and how they should be addressed. The paper ends with a set of program suggestions addressing these water-related difficulties.
\end{abstract}

Keywords Water access $\cdot$ COVID-19 $\cdot$ WASH; SDG $6 \cdot$ Drinking water $\cdot$ Mekong Region

Supplementary information The online version contains supplementary material available at https://doi.org/10.1007/s00267022-01616-9.

Boripat Lebel

boripatlebel@gmail.com

1 Unit for Social and Environmental Research, Department of Social Science and Development, Faculty of Social Sciences, Chiang Mai University, Chiang Mai, Thailand

2 University of Yangon, Yangon, Myanmar

3 Western Highlands Agriculture and Forestry Science Institute, Dak Lak, Vietnam

4 Department of Environmental Engineering, Faculty of Engineering, National University of Laos, Vientiane, Lao PDR

5 Inland Fisheries Research and Development Institute, Fisheries Administration, Ministry of Agriculture, Forestry and Fisheries, Phnom Penh, Cambodia

6 International Water Management Institute, Regional Office for Southeast Asia, Vientiane, Lao PDR

\section{Introduction}

The COVID-19 pandemic has underlined how access to clean water for drinking, hygiene, and other household uses is still an important issue for vulnerable communities in both developing and developed countries (Hannah et al. 2020, Tortajada \& Biswas 2020). A survey of households in 23 low-income and middle-income countries in 2017-18 found almost $70 \%$ had water-related problems in the previous month that made them vulnerable to COVID-19 (Stoler et al. 2021). A review of water, sanitation and hygiene (WASH) measures adopted in 84 countries showed that, while hygiene and infection prevention has been widely promoted, support for vulnerable households was often weak and coverage incomplete (Giné-Garriga et al. 2021). Inadequate water and sanitation infrastructure are frequently identified obstacles to improving hygiene practices, and thus reducing risks of COVID-19 infection (Howard 2021); for example, in remote Alaskan native 
communities in the United States (Eichelberger et al. 2021), and rural villages in Odishi, India (Bauza et al. 2021). Low socioeconomic status (Aregu et al. 2021), lack of formal rights (Larson 2020, Tanana et al. 2021), gender inequalities (Islam et al. 2021), and skewed power relations (Corburn et al. 2020, Stoler et al. 2021) are other sources of obstacles.

The purpose of this study was to better understand the main obstacles to household water access in vulnerable communities in the Mekong Region and identify ways they might be addressed in the context of the COVID-19 pandemic. This paper focuses on the perspectives of 50 government officials, and development or health experts interviewed from five countries in the Mekong Region (Cambodia, Laos, Myanmar, Thailand, Vietnam). This qualitative evidence was complimented with selected observations from a quantitative survey of residents in 15 vulnerable communities reported in detail elsewhere (Lebel et al. 2022). Previous work in the Mekong Region on issues of water access, supply, and quality provide a starting point from which to ask questions about the impacts of COVID-19.

Access refers to having the capabilities and entitlements to use a water source or system to meet at least basic needs (Gupta \& Lebel 2010). Residents in central Yangon, Myanmar, for instance, have had access to piped water for more than 150 years (Ko \& Sakai 2021), whereas today in peri-urban Yangon, the majority of informal settlement dwellers living along the river banks do not have access to tap water (Groot \& Bayrak 2019). Instead, they had to buy water of dubious quality at high prices from vendors. Perceptions of tap water quality and familiarity with it as a source are important to whether it is drunk or not in central Yangon (Ko \& Sakai 2021). In this example, differences in access to the tap water system are related to location and land ownership status. It is unclear if the COVID-19 pandemic had any significant impacts (positive or negative) on access to water in informal urban settlements like this or other highly vulnerable communities in the Mekong Region.

Supply refers to the physical availability and social allocation of water for household uses. Studies in Can Tho City, Vietnam, suggest that abilities to access alternative water resources to formal tap water system may reduce the risks of water shortages (Allen 2019), but another study showed that households that use multiple water sources had higher rates of illness (Neumann et al. 2014), underlining the importance of considering water quality in addition to supply volumes. In one site in Northern Vietnam, reservoirs traditionally used to harvest and store rainwater for the dry season were removed to construct a coal power plant (Nga 2018). Residents were provided with treated tap water from the river, but did not trust the quality of the water and found the supply unreliable, so they shifted back to collecting rainwater. These two examples illustrate interactions between access, supply, and quality. It is unclear if the COVID-19 outbreak in the short-term disrupted supplies or whether it renewed longer-term commitments to improving the supply of water to vulnerable communities in the Mekong Region.

Quality refers to the properties of water at various points from source to use, with an emphasis here on being safe to drink and clean enough for washing hands. Ethnic minorities living in upland areas of Northern Thailand obtain drinking water from mountain streams, shallow wells, or buy commercial bottled water (Sudsandee et al. 2020). In this latter study, all samples from mountain water supply systems were found to be contaminated. Groundwater wells, a potentially valuable drinking water source in periurban Chiang Mai, Thailand, were contaminated with $E$. coli and Enterococcus despite the use of "improved" sanitation systems (Chuah \& Ziegler 2018). In another suburban study, contamination of rainwater collected for drinking, could be explained by the lack of regular cleaning of rainwater urns (Vannavong et al. 2017). Water quality issues have not been addressed in most studies on the impacts of the COVID-19 pandemic, so its importance to meeting drinking water needs and the effectiveness of hygiene programs is still unclear.

The distinct vulnerabilities of women and men, elderly and children, migrants and residents, to the impacts of COVID-19 may intersect with water access, supply, and quality in differing ways. A review of WASH interventions in Myanmar focussed on internally displaced people, identified access to sanitation facilities by women, children, and the disabled as key gaps (Domini et al. 2020). While women in Vietnam were seen by officials as the primary beneficiaries of improved domestic water supply services, they had little recognized role in planning, maintenance or decision-making (Thai \& Guevara 2019). WASH initiatives can be an entry point to women's empowerment and contribute to gender equality (Leahy et al. 2017). A study of women-owned piped-water businesses in Cambodia also found evidence of empowerment, while observing persistent gender norms on mobility and household duties that limited income generation (Grant et al. 2019). It is unclear how COVID-19 interacted with household water uses or needs of women, children, the elderly or disabled in the Mekong Region.

Taken together, this past work on water use of vulnerable households in the Mekong Region suggests that the importance of COVID-19 impacts with respect to problems of water access, supply, and quality are likely to vary among types of vulnerable communities. Another expectation was that the perspectives of government officials on solutions may vary by country and sector, as well as differ from that of residents. Finally, while all five countries have made progress in pursuing targets under Sustainable 
Development Goal 6 (SDG 6) - which aims to "ensure availability and sustainable management of water and sanitation for all" (United Nations 2015) - significant or major challenges remain, and are likely to have been exacerbated by the COVID-19 outbreak (Sachs et al. 2021).

\section{Methods}

\section{Study Region}

This study was conducted in five countries in the Mekong Region: Cambodia, Laos, Myanmar, Thailand, and Vietnam. Thailand is now classified as an upper middle-income country, whereas the other four are considered lower middle-income countries (World Bank 2020). The first confirmed COVID-19 case outside China was a Chinese tourist visiting Thailand (13 January 2020). By 24 March 2020, the other four countries had also had their first case. Government efforts in the five countries to control spread of the disease followed similar timelines, for example, the first round of border closures to foreign visitors began in March 2020. As of 23 August 2021, the incidence of COVID-19 per hundred thousand population, based on online datasets (Dong et al. 2020), were from lowest to highest: Lao PDR (174), Vietnam (361), Cambodia (541), Myanmar (691), and Thailand (1507).

\section{Key Informant Interviews}

The interviews covered views on how government programs and policies helped people cope with impacts of the COVID-19 outbreak, starting broadly and then asking specifically about access, supply and quality of water for drinking, hygiene and other household uses in vulnerable communities. Informants were also asked about what else should be done and their views on the merits of pursuing four measures: improving reliability of water supply; improving quality of water supplied; expanding dry season storage; and providing low-income households with free alcohol gel for washing hands. In a few cases, we searched online for additional details about projects and policy issues raised in the key informant interviews. Any such sources used, mostly newspaper articles and press releases, are cited in the text.

Altogether 50 interviews were done, primarily between 6 May and 30 June 2021 in the five countries: Cambodia (6), Myanmar (7), Laos (10), Thailand (17), and Vietnam (10). Four late interviews were done in November 2021. By major stakeholder groups, the distribution was: 40 government officials, including from water (13), health (10), other (12), local (5); and 10 non-state actors, including from NGOs (5), academics (4), private consultants (1).
Interviews were conducted in local languages, mainly via online or telephone calls, and occasionally in person. When consent for recording was provided, the interviews were later transcribed. When interviewees asked not to be recorded, notes and summaries were made instead. In some cases, the informant asked to type their responses in their own time and send back to the researchers. Interview documents were translated into English for coding and analysis using the NVIVO 12 software.

In the results section, references to individual interview sources are shown with an interview number superscript. The full list of interviewees and their anonymized affiliations is provided in Table 1 of the Supplementary Materials.

\section{Survey}

In-depth interviews were not done with members of the vulnerable communities, as this would require extended travel by the researchers and long face-to-face interaction, increasing COVID-19 risks to all. Instead, we drew on a quantitative survey of largely closed questions that could be administered simply and quickly, often with trained local data collectors. Our primary source for information on the views of members of vulnerable communities, therefore, was a survey of 1559 individuals in 15 locations across five countries in the Mekong Region (Table 1). The surveys were mostly done between 20 January and 21 April 2021, except for a few late responses in Myanmar up to 2 June 2021.

In this paper, we focus on just a small part of the survey questionnaire dealing with support for interventions (same as those noted above for other stakeholders) and a few indicators of vulnerability and household water difficulties because of the COVID-19 outbreak. Vulnerability indicators included ethnic minority status, not having a formal education, and daily pay for work. For water difficulties, this included items related to access, supply, and quality. For drinking water, for example, this included "having to drink water that smelt, looked or tasted bad," disrupted delivery, water becoming more expensive, and being impacted by drought. A more detailed description of the data collection methods, and an analysis of the full quantitative survey appears in a companion paper (Lebel et al. 2022).

\section{Results}

\section{Water Access}

The findings below are organized around the inter-related issues of water access, supply, and quality. In the past year, many respondents from 15 vulnerable communities had experienced not having enough clean water to drink (48\%) 


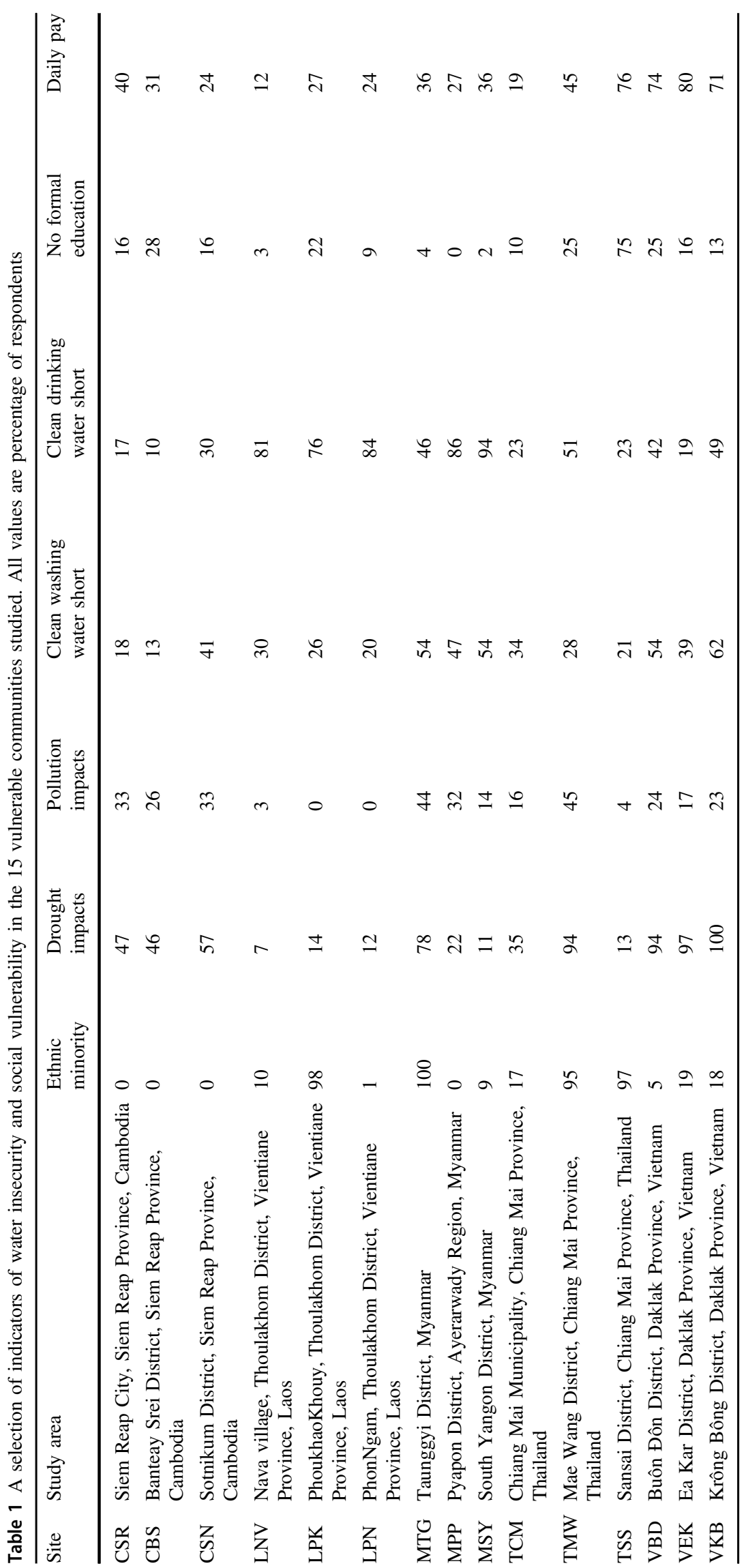


or wash hands $(36 \%)$. There were some differences among vulnerable communities (Table 1).

\section{Water service areas}

A long-term approach to COVID-19 recovery and reducing water access problems is to extend water distribution, for instance, by expanding infrastructure within or adjacent to existing service areas or developing a new source. In Thailand, the Provincial Waterworks Authority "budget is limited and the installation of pipes to expand area serviced must be worth the investment." ${ }^{30}$ The latter sentiment, an example of the corporate logic of fee-charging public water authorities. The quickest way to get clean water to an unconnected community is through a request to the subdistrict (TAO) or local government. The local government will then cooperate with the waterworks authority, "which is ready to assist." 28 Through this pathway, the work will be done more quickly as "the budget will be allocated faster." 28 According to an NGO worker, if you are not the main village, but a small and remote one, then "you will be among the last villages to be helped. It is local politics."27 Furthermore, local authorities are adept at "pushing the burden onto people in the community to take responsibility" 27 for securing their own water resources.

In Laos, projects in remote areas may be difficult to access by road in the rainy season, hindering development of water infrastructure. ${ }^{7}$ Some places where NGOs work "have no vehicle access due to poor road conditions, and thus need to walk about 10-20 kilometers, carrying things to the villages." 16 Another difficulty for water systems in remote locations is a lack of electricity, in which case one option is - if have enough funds - to use a solar-powered pump. ${ }^{7,13}$

Apart from remoteness, capacities to provide water services are often limited by budgets. If budget is available but limited, one approach is to "make two or three more watering points in the community," 8 and when more funds are available connect the water system directly to each house. In the context of COVID-19, it is desirable to have direct connections, as this helps reduce risks of contaminated supply points, and makes maintaining social distancing easier than when collecting water from a shared community access point. ${ }^{7}$ Infrastructure within the home, including taps, washing stations, storage, and latrines make it easier to follow good hygiene practices, but cost money. Helping vulnerable groups cope with the impacts of COVID-19 is "not only about water, it is also about WASH, or sanitation and hygiene, hardware and software."9

Government policy in Laos is for all people to have access to WASH services in line with SDG 6, but "need assistance from outside the country." An official in the Ministry of Health in Laos explained plans for a program supported by WHO to upgrade tap water systems "for all, not only for vulnerable groups" to be safe to drink. ${ }^{13}$ Informants from Laos, in particular, were reluctant to acknowledge vulnerable groups, instead emphasizing "access for all".

\section{Cost of water services}

The cost of water services limits access. Writing in April 2020, Horn Chanvoitey of Future Forum in Cambodia argued that the impending COVID-19 outbreak "exposes one of the Kingdom's great inequalities: access to clean water" (Chanvoitey 2020), while an official admitted that "the poor are lacking the ability to connect to clean water services" (Koemsoeun 2020).

Governments in most areas reduced water prices in service areas for a couple of months during the COVID-19 pandemic; some also reduced connection charges or extended due dates for service payments. Thus, in Thailand, the Provincial Waterworks Authority reduced water fees by $10 \%$ for two monthly billing cycles, first in February-March 2021, then again in May-July 2021. ${ }^{28,34}$ In Laos, the Water Supply Enterprise in Vientiane Province reduced water fees by $5 \%$ for 3 months for all persons, no focus on the vulnerable or poor. ${ }^{11}$ Another Lao official with the Department of Water Supply, said they had a program for free household water connections. ${ }^{8}$ In Vietnam, cuts to water prices were accompanied with cuts for electricity and telecommunication services in areas impacted by COVID-19 control measures such as lockdowns (Tu \& Tuan 2021). Across countries, these pricing-related measures largely apply to less vulnerable communities already in service areas - many other water insecure households do not benefit.

Those who live in the northern parts of Pindaya, Myanmar, for instance, must buy water "from the seller who takes the water from an urban lake" or a Monastery tube well. ${ }^{18}$ Plans are to drill tube wells and concrete storage tanks in five villages - a village water committee has already been established to maintain the system. ${ }^{18}$ In upland sites in Thailand, access to clean water is very expensive if must cart in by truck, so it is a last resort when other sources are unavailable. ${ }^{27}$

High prices of bottled drinking water may also limit access for the poor. Thus, governments need to "work closely with the private sector," namely drinking water factories, to "control the prices of drinking water and make sure that consumers are not taken advantage of during the COVID-19 outbreak."12 Respondents were more likely to report that drinking water became more expensive as a consequence of the COVID-19 outbreak in Myanmar (29\%), Cambodia (25\%), Thailand $(24 \%)$, and relatively less likely in Laos (5\%) and Vietnam (3\%). 
An important coping response to high prices was to switch to lower cost water sources. In the study sites in Vietnam, the poor and those whose income was greatly reduced by the COVID-19 outbreak, switched to boiled water from wells to drink rather than spend money on bottled water. ${ }^{42,46}$ In Myanmar, some people "cannot afford to buy bottled water, so they used river water for drinking. Consequently, people suffered from other health problem." 22 People were more likely to switch to lower quality sources as a response to COVID-19 in Vietnam (26\%) than other countries (6-11\%).

Extra expenses at home, including for water, may be a difficulty for low-income households, especially if COVID19 also resulted in sudden unemployment. ${ }^{36}$ To some extent financial assistance may help cope with rising costs or loss of income. In Thailand, access to government assistance related to COVID-19, however, required an identity card, and in several instances, a smart phone, effectively putting key resources beyond reach of the most vulnerable individuals. $^{35,49}$ Nevertheless, during 2020, survey respondents from Thailand (64\%) and Myanmar (57\%) were much more likely to have received formal financial assistance than those in other countries (2-9\%).

\section{Rights to water services}

An official in Thailand acknowledged "there are still people who do not have access to clean water, including some ethnic minority communities and foreign workers." 31 Thus, "people living outside the service area, for example, ethnic groups living in the uplands, won't receive water services from the Provincial Authority." 28 They must seek support from other government offices. The "cardless" in Thailand, not recognized as citizens and thus without an identity card, face many difficulties accessing government services. The identity card is also linked to a house registration document, which is needed to request for water or electricity connection. $^{36}$

Residents of informal settlements in Myanmar are without the land documents they need to access treated and piped water, so they "have to use river water for their domestic uses, as there is no clean water access for them."20 During the COVID-19 lockdown measures, an identity card was needed to be displayed when moving between areas. In Myanmar, "migrant workers who do not have legal registration in the township are among the most vulnerable." 20 Rights to water services, in practice, are not secure when individuals lack an identity card, house registration, and land documents.

Due to the COVID-19 pandemic, people "have to use more water in their daily activities than in normal times in order to" wash hands to prevent the spread of the disease, but some cannot follow the guidelines as they did not have enough water. ${ }^{23}$ The COVID-19 "crisis is a stark reminder that the Cambodian government has not sufficiently addressed the issue of insufficient access to clean water and sanitation" (Chanvoitey 2020).

Lack of specificity with regards to vulnerable groups has been an important limitation in strengthening access. In the COVID-19 response in Laos, "there is no specific programs for elderly, disabled, women and girls." 14 Similarly, in Myanmar, most government support programs are for all people, under the policy principle of "no one left behind."19 Nevertheless, the value of more targeted programs was acknowledged by some officials, for example, one argued "government support programs should place more emphasis on specific vulnerable groups like the elderly, migrants, children and disabled." 21 School and childcare center closures impact children and their caregivers; children no longer eat lunch or drink milk provided at school. ${ }^{36}$ Younger children need to be supervised, limiting the time parents can earn an income outside the home. ${ }^{36}$

Likewise, residents of informal settlements suffer from lack of access to clean water during the pandemic, and therefore should be targeted for assistance by specific supporting programs. ${ }^{20}$ In Thailand, this is difficult to provide as they lack house registration documents. ${ }^{29}$ Regardless, an official argued that "government agencies must have a plan, and from a humanitarian perspective must help" those without access to clean drinking water. ${ }^{31}$

In summary, the COVID-19 pandemic increased awareness of water access issues among government officials concerned about WASH services. Prices of tap water, for example, were lowered. There was no evidence of changes to formal rights of vulnerable communities to access water services.

\section{Water Supply}

\section{Dry season shortages}

Dry season shortages were an important reason for disrupted water supplies. Half of the surveyed respondents (49\%) said their household water sources were impacted by seasonal drought. Respondents in upland sites were more likely than those in urban sites to have their water supplies impacted by seasonal drought. Households impacted by drought were more likely than those not so impacted to support actions to increase community water storage.

In Dak Lak, Vietnam, water shortages are most common towards end of the dry season (March-May), with impacts greatest in remote areas, ethnic minority villages and poor households. ${ }^{46}$ Those with shallow dug wells are impacted more than those with deeper drilled wells, as the former dry out. $^{38,43}$ Women are impacted more than men because they "have to carry water home from their neighbors [well]." ${ }^{40} \mathrm{~A}$ lack of water for hygiene impacts "not only COVID-19, but 
other diseases such as hand, foot and mouth disease" among children. In 2020, the outbreak of COVID-19 coincided with water shortages, exacerbating the challenges of maintaining hygiene for those without access to tap water. ${ }^{38}$

Increasing water storage is one solution recommended by officials and experts in all countries. In Laos, officials encouraged villagers to collect rainwater and build big tanks to store water. ${ }^{14}$ In Cambodia, communities are encouraged to extend public ponds and drill community wells to help improve dry season water storage. ${ }^{1}$ Households are also encouraged to collect and store rainwater. Financial resources are important to making own water storage pond, as it is costly to make a pond big enough to last the dry season. ${ }^{25}$ Moreover, "water shortage problems for personal hygiene became worse in the pandemic period." 20 In Myanmar, the government had a program, "not only for the COVID-19 period but for the long-term water security," for some villages to build water tanks to store harvested rainwater. ${ }^{18}$

Drilling wells is another important option to secure water supplies. In Laos, wells are usually more than 60 meters deep with a standard minimum of 40 meters. ${ }^{15,16}$ In Vietnam, wells were around 60 meters. ${ }^{39}$ Drilling wells is expensive $^{41}$ so lower-income households depend on community drilling projects funded by the state or NGOs. ${ }^{42}$ Government programs "support drilled wells for communes that are short of water in the dry season and do not have access to tap water." 44 Even so, in Buon Don, Vietnam, "many drilled wells do not have water because of the rocky terrain." 45 In peri-urban sites, such as those in Thailand, water quality in shallow wells is often poor. ${ }^{24}$ Survey respondents in Vietnam (87\%) were the most likely, and in Thailand the least likely (5\%), to use groundwater wells as a source of drinking water - with the other three countries being intermediate (30-38\%).

\section{Service disruptions}

The dominant view of officials was that the provision of tap water was unaffected by the COVID-19 outbreak. In the city of Vientiane, Laos, "local communities can get access to clean water to use in toilets/bathrooms, washing hands, and in their house."13 The city has a good system so the impacts of COVID-19 were small, "but in rural area impacts were greater."7 In Vietnam, "COVID-19 did not have much effect on people's access to safe drinking water and sanitation." 38 A district waterworks official in Thailand said that "the spread of COVID-19 was not affected because water production was maintained as normal." 30 In Thailand, "the spread of the COVID-19 virus has not directly affected people's access to clean water in areas that use water from the Metropolitan Waterworks Authority."34

At the same time, a regional waterworks official in Thailand noted that for maintenance and servicing, the "key problem they encountered was entering areas designated as red zones for controlling spread of COVID-19."29 In Laos, some water supply projects were abandoned or significantly delayed following disruptions to work caused by the COVID-19 outbreak. $^{7}$ With Vientiane city and province locked down, experts cannot come to work, and thus water supply improvement programs were delayed..$^{9,13}$

In Myanmar, at times of critical shortages prior to COVID-19, "water was provided house-by-house, but during outbreak could only fill concrete tanks in middle of village" due to concern about disease transmission. ${ }^{18}$ "Moreover, despite that some clean water is accessible, it is not enough quantity for their daily use, especially water for handwashing and hygiene." 21

As a temporary solution, alcohol-based hand sanitizers were distributed for free in some areas in each country for short periods, often as part of hygiene information campaigns or private donation initiatives in response to COVID-19. Hand sanitizers were otherwise too costly for residents in vulnerable communities. ${ }^{9,23,27,49}$ In Laos, "there are many households that cannot get alcohol gel for washing hands, because they lack the money needed to buy it." 14 When they were given a bottle of gel they had to use it sparingly - "so we use alcohol gel for washing hands only when we go outside, and we use soap when we stay at home where we often wash our hands."7

Support for programs among residents surveyed to "provide low-income households with free alcohol gel for washing hands" was higher in Thailand (46\%) and Cambodia (44\%), than in Laos (28\%) and Myanmar (22\%). Government officials in Laos and Myanmar pointed out that they had supplies and budgets for only a fraction of those in potential need. ${ }^{15,18} \mathrm{~A}$ medical officer said they prioritized "providing hand gel to villages with water access problems, in order to save water, while acknowledging we also have to create water sources for them in the long term.",23

Drinking water supplies were temporarily disrupted by the COVID-19 outbreaks in some locations in Laos, as "local authorities did not allow them access to the village to deliver drinking water, to all outsiders." ${ }^{10}$ Later on the provincial and district COVID-19 operation units intervened and instructed that drinking water was to be delivered as normal. ${ }^{10}$ Overall, a quarter of the households $(23 \%)$ surveyed in vulnerable communities experienced disrupted delivery of drinking water because of the COVID-19 outbreak. This is a larger group than implied in interviews with state officials and NGOs. Just under half of households overall supported interventions to improve the reliability of water supplies.

\section{Community participation in water supply}

In Myanmar, the policy gap between national level and ward level, spanning six levels in the administrative 
hierarchy, is large and difficult to navigate. ${ }^{20}$ Most policy and regulation are top-down, with many limitations emerging, leading an informant to argue an urgent need to "have feedback from both implementers and local people.",1 Moreover, a recurrent problem for established but vulnerable communities in Thailand looking to engage with the state is that there are "too many players" 36 with stakes in water resource management. An academic characterized the COVID-19 governance challenge: "Understand that the public do not have a role in offering solutions or ideas for what the government should do, what measures it should take, to help the people. There are no people at all; there are experts and civil servants as far as the eye can see. There is no civil society." 49

While the reliability of water supplies to households can be improved by drilling wells to exploit groundwater and concrete tanks to store rainwater, community level projects typically require "a lot of negotiation with villagers" around choosing locations for wells, tanks and pipe networks as land-uses are impacted. ${ }^{18}$ Water projects are managed " $t o$ allow the community to participate, meaning that villagers have to help dig and lay the pipes themselves. There is no budget for digging and laying pipes." 32 There is also training for the water management committee on how to use the equipment and reduce risks of contamination, for instance, through rules regarding allowable activities near the well. ${ }^{16}$ Communities may be required to establish a water fund based on household contributions and use it to pay for electricity, maintenance, and repairs. ${ }^{7,13}$

In Thailand, one community managed a coin-operated reverse osmosis drinking water filtration and treatment system. The system is popular because it is cheap and conveniently located along the main road, and thus also used by other villages. ${ }^{32}$ The sales are sufficient to replace filters and cover costs of electricity and a technician when repairs are needed. ${ }^{32} \mathrm{~A}$ village fund committee including headmen and sub-district office manages the dispenser, a separate committee to that manages the ageing village mountain water supply. ${ }^{32}$ Water management according to community agreed rules in the mountain system is impor$\tan { }^{36}$ for water allocation: "There will be discussions at the community level about how much water can be used, because we are upstream. How much will we have to use, and besides, we will have to let people downstream use it too." 27 Such social allocation systems were maintained and proved useful during the COVID-19 outbreak.

In summary, water supply was only disrupted for short periods, if at all, by the COVID-19 outbreak. Dry season shortages remained a key source of supply disruptions in some communities and impacted on hygiene measures. The favored long-term response being to drill more (and deeper) wells or larger storage ponds.

\section{Water Quality}

\section{Treatment \& monitoring}

Groups vulnerable to poor water quality and COVID-19 include "migrant workers, casual workers, and low-income families in the township." 22 And "even though they wash their hands regularly, the quality of the water they access is not good for use." ${ }^{20}$ A minority of residents surveyed in the past year "had to drink water that smelt, looked, or tasted bad" $(17 \%)$ or "wash hands with water thought was dirty or unsafe" (23\%). In the vulnerable communities studied in Myanmar, "for drinking, most use bottled water, but for the poor families, they must use both pond water and river water for both cooking and drinking, although it is not safe for their health."

Around half of the individuals surveyed (53\%) agreed that actions should be taken to "improve the quality of water supplied so it is safe to drink". Experts largely concurred with some bureaucrats, seeing it as a core mission of governments. ${ }^{31}$ In Thailand, "the master plan stipulates that every village must have clean drinking water. It is written in the plan, but actually doing it according to the plan is difficult." water has been transferred to local government" alongside budgets, but as they also have large mandates, the result is that providing clean water is not always a priority. ${ }^{31}$ Adequate budgets for maintaining water treatment systems, replacing filters, for example, is also important. ${ }^{49}$

The Department of Health in Thailand monitors water quality for the Metropolitan Waterworks Authority. ${ }^{34}$ Since the first wave of the COVID-19 outbreak, the Environmental Health Working Group has been monitoring for potential contamination and coordinating the management of water quality in Chiang Mai province. ${ }^{33} \mathrm{~A}$ key technical measure was to raise free chlorine levels from $0.2-0.5 \mathrm{ppm}$ to more than $1.0 \mathrm{ppm}$. The Department of Groundwater Resources introduced additional measures for the water production teams, in order to reduce risks of COVID-19 spread, including wearing of gloves and hats, and additional cleaning routines. ${ }^{31}$

Local village tap water supply systems in Thailand normally do not get government support to use disinfectants. A public health academic recommended that "the government should promote the addition of chlorine to reduce the contamination of pathogens in the community or village water supply systems." ${ }^{48}$ Some managers learn about the use of chlorine, but face another obstacle: "villagers do not want to use water that smells of chlorine." 48 Even if water meets standards where it is produced, if the pipe system is not well-maintained, tap water may not be safe to drink. $^{48}$ 


\section{Drinking water production}

Locally produced drinking water "is cheap and easy to buy, but when we look back on the water production process, some small drinking water plants might not be up to standard." ${ }^{48}$ Small bottling companies that don't have their own water treatment equipment buy water from a larger producer, and in the handling, for instance, putting on caps, there may be contamination. ${ }^{48}$ Governments need to monitor and enforce laws, for example, when failing to meet standards, and "provide water that is really clean to the people." official in Thailand summarized that "so far, no coronavirus 2019 has been detected in drinking water, and based on current information, the risk of contamination of drinking water is low." 47

Drinking water dispensers were not used in study sites in Cambodia and Laos, uncommon in Vietnam (6\%), and more familiar in Myanmar (21\%) and Thailand (48\%). A stable electricity supply is an important pre-requisite to having reverse osmosis water treatment facilities, including coin-operated dispensers. ${ }^{27}$ On-going maintenance, for example, to change filters, is also important for water quality. ${ }^{48}$ Monitoring show that "coin-operated water dispensers, used by laborers and low-income people, are easily contaminated, ${ }^{48}$ and as a shared access point, a potential source of COVID-19 infection. ${ }^{48}$ Local government in Chiang Mai recognized the need to keep coinoperated water dispensers clean, ${ }^{32}$ especially during the COVID-19 outbreak.

\section{Protection of sources}

Upland residents and officials, although they live or work in different elevation zones in the landscape, had similar views (reasoning) regarding the importance of watershed forests for protecting water resources. To protect water sources from degradation, "the conservation and restoration of watershed forests" is key to "sustainable and secure water resources." ${ }^{36}$ In the upland communities in Chiang Mai, an NGO member explained how "we use our knowledge and beliefs in water management, such as taking care of watershed forests. There are prohibitions on disturbing watershed forests." ${ }^{27}$ An official from a water enterprise serving Vientiane underlined that "need to reserve the forest in upstream due to climate change issue, it is very significant for water supplies." 11 Dry season shortages are understood by these actors to be a consequence of deforestation. ${ }^{8}$

In rural areas, "the community needs to understand that if we farm with dangerous chemicals, the water will become contaminated." 36 An important part of dealing with dry season water challenges is for the "community to take measures to protect their water sources." In urban areas, lockdowns during the COVID-19 outbreak made solid waste and wastewater management more challenging, especially from medical facilities. ${ }^{48}$ Groundwater wells, according to one official in Laos, should be separated from toilets by at least 30 meters. ${ }^{16}$ During COVID-19 pandemic, some authorities and local communities paid more attention to the sanitation requirements of water systems. ${ }^{16}$

In summary, water quality issues have been a concern of both residents and officials in all five countries. The COVID-19 outbreak amplified concerns about the importance of clean water for drinking and hygiene.

\section{Discussion}

The key finding of this study was that, despite rapid and pervasive social and economic development across the Mekong Region, difficulties in accessing sufficient clean water for drinking and hygiene persist in certain vulnerable communities. Experiences in migrant worker camps, informal city settlements, and remote minority villages, suggest that these difficulties, exposed by the COVID-19 outbreak, are routinely underestimated by officials or fall into institutional cracks. In normal times, these vulnerable communities are rarely visited by water agencies. Communities are expected to handle problems themselves, and thus the limitations of water systems pass largely unnoticed. Various agencies responsible for constructing water infrastructure or providing treated water have their own service areas, budgets, and procedures for adjusting water distribution, adding delivery points, opening new connections or developing new water sources. No one is directly responsible for water systems in these communities. Coordination across government agencies, as well as collaboration with residents and other non-state actors (Corburn et al. 2020), helps secure project financing (Howard et al. 2020), and ensure implementation leads to improved access.

Limited rights, high prices, and remote locations were common obstacles to water access. Rights to water, in practice, are not secure when individuals lack an identity card, house registration, travel or land documents. High prices of water for drinking or hygiene are an issue for lowincome households, in particular those on daily wages or whose livelihoods have been disrupted by COVID-19 measures such as lockdowns or business and border closures. In an earlier study in rural Vietnam, high connection fees were the main reason poor households did not access piped water (Carrard et al. 2019). In the current study, reduced water service fees of around $10 \%$ for a couple of months during the COVID-19 outbreak, while popular, did not benefit the most vulnerable households, for instance, in informal urban settlements without metered connections. The free water directive introduced in Ghana went much 
further than the public utilities in the Mekong Region, promising six months of free water to domestic users, but also struggled to reach poor and water insecure households (Smiley et al. 2020). Remote communities faced with seasonal shortages in the availability of clean water lie beyond current service areas of water authorities, and do not have sufficient funds to develop new water sources by themselves. A sustained effort is needed to identify, assist, and empower water insecure individuals at risk, as they are not automatically visible to programs catering to the general population, even in the context of a pandemic response with its emphasis on reducing transmission.

In this study, the COVID-19 outbreak temporarily disrupted supplies in some sites, and interrupted water programs or maintenance in others. A global commentary suggested that the combination of a drought and pandemic could be disastrous with severe impacts on agricultural livelihoods, employment, and nutrition in local and wider food systems (Mishra et al. 2021). The sensitivity to drought of upland communities in this study was a source of concern to some officials and experts interviewed. In the uplands of Vietnam, for example, water shortages are common towards the end of the dry season. Residents drill wells, build storage ponds, and save water for domestic uses, sharing when they must. Governments and residents agree that further investments in drilling groundwater wells, rainwater harvesting structures, increasing storage, and watershed conservation are needed. Similar perspectives among stakeholders on ways to meet needs using local water resources are a starting point to improving supply, but is not enough - there must also be sufficient public investment for infrastructure to reach all households. Elsewhere in Vietnam, unreliable tap water services led people to access alternative sources (Allen 2019, Nga 2018). Regionally, there was little evidence, aside from reaffirmations of the importance of WASH programs, that the COVID-19 outbreak would stimulate improvements in the supply and allocation of water to vulnerable communities. Rather, early concerns that the outbreak may delay achievement of the SDGs (The Lancet Public $\mathrm{H}$ (2020)) still seem to hold, in particular, for the case of Myanmar (Sachs et al. 2021).

Perceptions of the importance of water quality problems often differed between officials and residents. In the uplands, water quality may be perceived as good by residents, but treatment is still essential given high rates of contamination (Sudsandee et al. 2020). In lowland settlements with improved sanitation, poorly sited and maintained toilets can still contaminate ground water used for drinking and hygiene in the household, causing disease outbreaks (Chuah \& Ziegler 2018). In dense informal settlements, these contamination risks are even higher. The high dependence on bottled drinking water in many of the vulnerable communities studied, reflects concerns with the quality of tap water and other alternatives. Contamination of water during handling and storage, shown to be important in other studies from the region (Shaheed et al. 2014, Vannavong et al. 2017), was also noted by interviewees in this study. Threats to water quality from contamination need to be addressed by investments in monitoring, treatment, and protection. In the longer-term, it is important to protect water sources from degradation (Hannah et al. 2020). Water quality was an important issue for vulnerable populations in the Mekong Region.

There was widespread agreement among residents and officials that women were more vulnerable and impacted more by COVID-19 than men - in line with expectations (Adams et al. 2021). Women use water in the household for cooking and cleaning, and were more likely to follow good handwashing hygiene practices (Lebel et al. 2022). Experts and officials, however, said very little about the roles of women in addressing water-related difficulties, or the benefits to women of solutions proposed or adopted. Officials in Laos, for instance, tended to discuss solutions to water access issues as being "for all" and were reluctant to emphasize special treatment for specific vulnerable groups. In other countries, perspectives were more diverse, and included calls for both greater humanitarian assistance to specific vulnerable groups, and for isolation or control of others seen as a threat of further disease outbreaks.

This study is one of the first to explore the implications of differences in stakeholder perspectives for programs aimed at improving water systems in the context of the COVID-19 pandemic. Public actors from different sectors or levels of government perceive and respond to problems of water access, supply, and quality differently, reflecting mandates and organizational interests. Water officials, when addressing immediate COVID-19 concerns, emphasized their actions taken to reduce risks of transmission through their services; whereas when addressing issues of water supply, they referred to expanding service areas or improving reliability of services. Health officials focussed on the COVID-19 crisis, when it came to water, were mostly concerned about ensuring adequate supplies of clean water to healthcare or quarantine facilities, and risks of contamination from wastewater. Officials with responsibilities for administrative areas at local or provincial levels have diverse planning and implementation responsibilities when it comes to water resources and COVID-19 responses. In general, local governments did not put improving access to water for vulnerable groups as a local development priority. These differences in perspectives help explain the institutional cracks that leave vulnerable communities underserved.

\section{Conclusions}

The views of residents, officials, and experts regarding both the significance of water access, supply, and quality issues, 
and what needs to be done to address them, while often overlapping, also diverged in a few important areas. Based on these observations and other findings of this study, we have five program suggestions.

First, special programs are needed to help highly vulnerable communities gain secure access to sufficient clean water for drinking and hygiene during the COVID-19 pandemic. Programs aimed at the general population are not enough. Coordination mechanisms are needed, for example, an inter-ministerial working group at the provincial level, to ensure that no one is left behind.

Second, emergency measures under COVID-19 outbreak should be linked into recovery programs in a way that leaves water systems better prepared for the next pandemic. This could start by ensuring that weaknesses of water systems, exposed by the outbreak, are documented and the lessons shared, so that these weaknesses can be addressed by postcrisis recovery programs. Costs are always an issue. One way to prioritize needs and attract external funding is to explicitly link efforts to improve water systems to WASH programs and SDG 6 targets for drinking water and sanitation.

Third, as the barriers to improving water supply and quality in vulnerable communities are diverse and contextspecific, it is important that households are consulted in the design of WASH programs and the development of water resources. This includes evaluation of water supply infrastructure, treatment technologies, and institutional arrangements such as management committees and water service fees. Doing so would help narrow the gap between the experiences of vulnerable people and the views of officials and their experts.

Fourth, the private sector played an important role in the provision of drinking water. Quality and prices of water, as well as the adherence to hygiene practices in transport and at shared water collection points, however, need to be monitored and regulated by governments. In terms of outbreak context, greater attention is needed on the regular cleaning and servicing of shared water points such as coin-operated dispensers. In terms of longer-term recovery and preparedness, the public needs greater reassurance of the reliability of tap water quality, otherwise bottled water systems will continue to predominate drinking water supplies.

Fifth, the role of the natural environment in protecting water resources needs to be more widely recognized by residents and officials. In the uplands, support for developing local water systems, for instance, could be linked to commitments to protect upper tributary watersheds; while in the lowlands, sources of pollutants and contaminants need to be managed, including from agricultural fields, human settlements, and industrial activities.

In conclusion, the findings of this study suggest that a combination of shorter-term and longer-term measures addressing water access, supply, and quality difficulties are needed to improve provisioning of clean water for drinking and hygiene in normal times, as well as during epidemics, in vulnerable communities in the Mekong Region.

Acknowledgements This study was supported by the Sustainable Mekong Research Network (SUMERNET) [Grant No. 100099231].

\section{Compliance with Ethical Standards}

Conflict of Interest The authors declare no competing interests.

Ethics Approval The study received approval from the Sustainable Mekong Research Network (SUMERNET) ethics committee prior to the research being undertaken.

Publisher's note Springer Nature remains neutral with regard to jurisdictional claims in published maps and institutional affiliations.

\section{References}

Adams EA, Adams YJ, Koki C (2021) Water, sanitation, and hygiene (WASH) insecurity will exacerbate the toll of COVID-19 on women and girls in low-income countries Sustainability: Sci, Pract Policy 17:86-90. https://doi.org/10.1080/15487733.2021. 1875682

Allen S (2019) Water scarce or water abundant? The case of Can Tho, Vietnam Urban Geogr 40:1030-1038. https://doi.org/10.1080/ 02723638.2019.1617009

Aregu MB, Kanno GG, Ashuro Z, Alembo A, Alemayehu A (2021) Safe water supply challenges for hand hygiene in the prevention of COVID-19 in Southern Nations, Nationalities, and People's Region (SNNPR), Ethiopia. Heliyon 7:e08430. https://doi.org/10. 1016/j.heliyon.2021

Bauza V, Sclar GD, Bisoyi A, Majorin F, Ghugey A, Clasen T (2021) Water, sanitation, and hygiene practices and challenges during the COVID-19 pandemic: a cross-sectional study in rural Odisha, India. Am J Tropical Med Hyg 104:2264-2274. https://doi.org/ 10.4269/ajtmh.21-0087

Carrard N, Madden B, Chong J, Grant M, Nghiêm TP, Bùi LH, Hà HTT, Willetts J (2019) Are piped water services reaching poor households? Empirical evidence from rural Viet Nam. Water Res 153:239-250. https://doi.org/10.1016/j.watres.2019.01.026

Chanvoitey H 2020. Covid-19 exposes the great inequality in Cambodian water access (16 April 2020). Southeast Asia Globe. https://southeastasiaglobe.com/cambodian-water-access-covid/

Chuah CJ, Ziegler AD (2018) Temporal variability of faecal contamination from on-site sanitation systems in the groundwater of Northern Thailand. Environ Manag 61:939-953. https://doi.org/ 10.1007/s00267-018-1016-7

Corburn J, Vlahov D, Mberu B, Riley L, Caiaffa WT, Rashid SF, Ko A, Patel S, Jukur S, Martínez-Herrera E et al. (2020) Slum health: arresting COVID-19 and improving well-being in urban informal settlements. J Urban Health 97:348-357. https://doi.org/10.1007/ s11524-020-00438-6

Domini M, Guidotti S, Lantagne D (2020) Temporal analysis of water, sanitation, and hygiene data from knowledge, attitudes, and practices surveys in the protracted humanitarian crisis in Myanmar. J Water, Sanitation Hyg Dev 10:806-817. https://doi.org/10. 2166/washdev.2020.025

Dong E, Du H, Gardner L (2020) An interactive web-based dashboard to track COVID-19 in real time. Lancet Infect Dis 20:533-534. https://doi.org/10.1016/S1473-3099(20)30120-1 
Eichelberger L, Dev S, Howe T, Barnes DL, Bortz E, Briggs BR, Cochran P, Dotson AD, Drown DM, Hahn MB et al. (2021) Implications of inadequate water and sanitation infrastructure for community spread of COVID-19 in remote Alaskan communities. Sci Total Environ 776:145842. https://doi.org/10.1016/j. scitotenv.2021.145842

Giné-Garriga R, Delepiere A, Ward R, Alvarez-Sala J, AlvarezMurillo I, Mariezcurrena V, Sandberg HG, Saikia P, Avello P, Thakar K et al. (2021) COVID-19 water, sanitation, and hygiene response: Review of measures and initiatives adopted by governments, regulators, utilities, and other stakeholders in 84 countries. Sci Total Environ 795:148789. https://doi.org/10.1016/ j.scitotenv.2021.148789

Grant M, Soeters S, Bunthoeun I, Willetts J (2019) Rural piped-water enterprises in cambodia: a pathway to women's empowerment? Water 11:2541. https://doi.org/10.3390/w11122541

Groot R, Bayrak MM (2019) Achieving water security in peri-urban Yangon: Exploring the local governance processes. Water Policy 21:980-998. https://doi.org/10.2166/wp.2019.058

Gupta J, Lebel L (2010) Access and allocation in earth system governance: water and climate change compared. Int Environ Agreem 10:377-395. https://doi.org/10.1007/s10784-010-9139-1

Hannah DM, Lynch I, Mao F, Miller JD, Young SL, Krause S (2020) Water and sanitation for all in a pandemic. Nat Sustainability 3:773-775. https://doi.org/10.1038/s41893-020-0593-7

Howard G (2021) The future of water and sanitation: global challenges and the need for greater ambition. J Water Supply: Res TechnolAqua 70:438-448. https://doi.org/10.2166/aqua.2021.127

Howard G, Bartram J, Brocklehurst C, Colford Jr JM, Costa F, Cunliffe D, Dreibelbis R, Eisenberg JNS, Evans B, Girones R et al. (2020) COVID-19: urgent actions, critical reflections and future relevance of 'WaSH': lessons for the current and future pandemics. J Water Health 18:613-630. https://doi.org/10.2166/wh. 2020.162

Islam SMD-U, Mondal PK, Ojong N, Bodrud-Doza M, Siddique MAB, Hossain M, Mamun MA (2021) Water, sanitation, hygiene and waste disposal practices as COVID-19 response strategy: insights from Bangladesh. Environ, Dev Sustainability 23:11953-11974. https://doi.org/10.1007/s10668-020-01151-9

Ko SH, Sakai H 2021. Perceptions of water quality, and current and future water consumption of residents in the central business district of Yangon city Myanmar. Water Supply. https://doi.org/ $10.2166 /$ ws. 2021.212

Koemsoeun S 2020. Clean water for all by 2025 (13 October 2020). The Phnom Penh Post. https://www.phnompenhpost.com/nationa 1/clean-water-all-2025

Larson R (2020) Water law and the response to COVID-19. Water Int 45:716-721. https://doi.org/10.1080/02508060.2020.1835422

Leahy C, Winterford K, Nghiem T, Kelleher J, Leong L, Willetts J (2017) Transforming gender relations through water, sanitation, and hygiene programming and monitoring in Vietnam. Gend Dev 25:283-301. https://doi.org/10.1080/13552074.2017.1331530

Lebel L, Navy H, Siharath P, Long CTM, Aung N, Lebel P, Hoanh CT, Lebel B (2022) COVID-19 and household water insecurities in vulnerable communities in the Mekong Region. Environment, Development and Sustainability. https://doi.org/10.1007/s10668022-02182-0

Mishra A, Bruno E, Zilberman D (2021) Compound natural and human disasters: Managing drought and COVID-19 to sustain global agriculture and food sectors. Sci Total Environ 754:142210. https://doi.org/10.1016/j.scitotenv.2020.142210
Neumann LE, Moglia M, Cook S, Nguyen MN, Sharma AK, Nguyen TH, Nguyen BV (2014) Water use, sanitation and health in a fragmented urban water system: Case study and household survey. Urban Water J 11:198-210. https://doi.org/10.1080/ $1573062 X .2013 .768685$

Nga DTT (2018) Water as human right: impact of Thai Binh 1 thermal plant project on domestic water supply of riverine people in Chi Thien village. Vietnam Kathmandu Sch Law Rev 6:79-85. https://kslreview.org/index.php/kslr/article/view/204

Sachs J, Kroll C, Lafortune G, Fuller G, Woelm F (2021) The decade of action for the sustainable development goals: Sustainable development report 2021. Cambridge University Press. https://www.sustainabledevelopment.report/

Shaheed A, Orgill J, Ratana C, Montgomery MA, Jeuland MA, Brown J (2014) Water quality risks of 'improved' water sources: evidence from Cambodia. Tropical Med Int Health 19:186-194. https://doi.org/10.1111/tmi.12229

Smiley SL, Agbemor BD, Adams EA, Tutu R (2020) COVID-19 and water access in Sub-Saharan Africa: Ghana's free water directive may not benefit water insecure households. Afr Geographical Rev 39:398-404. https://doi.org/10.1080/19376812.2020.1810083

Stoler J, Miller JD, Brewis A, Freeman MC, Harris LM, Jepson W, Pearson AL, Rosinger AY, Shah SH, Staddon C et al. (2021) Household water insecurity will complicate the ongoing COVID19 response: Evidence from 29 sites in 23 low- and middleincome countries. Int J Hyg Environ Health 234:113715. https:// doi.org/10.1016/j.ijheh.2021.113715

Sudsandee S, Fakkaew K, Keawdounglek V, Laor P, Worakhunpiset S, Apidechkul T (2020) Drinking water investigation of hill tribes: a case study in Northern Thailand. Int $\mathrm{J}$ Environ Res Public Health 17:1698. https://doi.org/10.3390/ ijerph17051698

Tanana H, Combs J, Hoss A (2021) Water is life: law, systemic racism, and water security in Indian Country. Health Security 19: S-78-S-82. https://doi.org/10.1089/hs.2021.0034

Thai NV, Guevara JR (2019) Women and water management: a policy assessment-a case study in an Giang Province, Mekong Delta, Vietnam. Asia-Pac J Rural Dev 29:77-97. https://doi.org/10. 1177/1018529119860949

The Lancet Public H (2020) Will the COVID-19 pandemic threaten the SDGs? Lancet Public Health 5:e460. https://doi.org/10.1016/ S2468-2667(20)30189-4

Tortajada C, Biswas AK (2020) COVID-19 heightens water problems around the world. Water Int 45:441-442. https://doi.org/10.1080/ 02508060.2020 .1790133

Tu A, Tuan V 2021. Vietnam cuts utility bills as part of COVID-19 relief (2 August 2021). VNExpress International. https://e. vnexpress.net/news/news/vietnam-cuts-utility-bills-as-part-ofcovid-19-relief-4333216.html

United Nations. 2015. Transforming our world: the 2030 Agenda for Sustainable Development. United Nations. https://sdgs.un.org/ 2030agenda

Vannavong N, Overgaard HJ, Chareonviriyaphap T, Dada N, Rangsin R, Sibounhom A, Stenström TA, Seidu R (2017) Assessing factors of E. coli contamination of household drinking water in suburban and rural Laos and Thailand. Water Supply 18:886-900. https://doi.org/10.2166/ws.2017.133

World Bank. 2020. World Bank Country and Lending Groups (Accessed 31 January 2022). The World Bank Group. https://data helpdesk.worldbank.org/knowledgebase/articles/906519-worldbank-country-and-lending-groups 